\title{
Antipsychotic medication non-adherence among schizophrenia patients in Central Ethiopia
}

\begin{tabular}{|c|c|}
\hline \multicolumn{2}{|c|}{$\begin{array}{l}\text { Authors: } \\
\text { Minale Tareke }^{1} \\
\text { Siranesh Tesfaye }^{2} \\
\text { Desalegn Amare }^{1} \\
\text { Tilahun Belete }^{3} \\
\text { Andargie Abate }^{1}\end{array}$} \\
\hline \multicolumn{2}{|c|}{$\begin{array}{l}\text { Affiliations: } \\
{ }^{1} \text { College of Medicine and } \\
\text { Health Science, Bahir Dar } \\
\text { University, Ethiopia }\end{array}$} \\
\hline \multicolumn{2}{|c|}{$\begin{array}{l}{ }^{2} \text { Department of Psychia } \\
\text { Felege Hiwot Referral } \\
\text { Hospital, Ethiopia }\end{array}$} \\
\hline \multicolumn{2}{|c|}{$\begin{array}{l}{ }^{3} \text { College of Health Science, } \\
\text { Psychiatry Unit, Department } \\
\text { of Nursing, Mekelle } \\
\text { University, Ethiopia }\end{array}$} \\
\hline \multicolumn{2}{|c|}{$\begin{array}{l}\text { Corresponding author: } \\
\text { Minale Tareke, } \\
\text { minale23@gmail.com }\end{array}$} \\
\hline \multicolumn{2}{|c|}{$\begin{array}{l}\text { Dates: } \\
\text { Received: } 17 \text { Apr. } 2017 \\
\text { Accepted: } 22 \text { Nov. } 2017 \\
\text { Published: } 05 \text { Mar. } 2018\end{array}$} \\
\hline \multicolumn{2}{|c|}{$\begin{array}{l}\text { How to cite this article: } \\
\text { Tareke M, Tesfaye S, Amare D, } \\
\text { Belete T, Abate A. } \\
\text { Antipsychotic medication } \\
\text { non-adherence among } \\
\text { schizophrenia patients in } \\
\text { Central Ethiopia. S Afr J } \\
\text { Psychiat. 2018;24(0), a1124. } \\
\text { https://doi.org/10.4102/ } \\
\text { sajpsychiatry.v24i0.1124 }\end{array}$} \\
\hline \multicolumn{2}{|c|}{$\begin{array}{l}\text { Copyright: } \\
\text { C 2018. The Authors } \\
\text { Licensee: AOSIS. This } \\
\text { is licensed under the } \\
\text { Creative Commons } \\
\text { Attribution License. }\end{array}$} \\
\hline \multicolumn{2}{|l|}{ Read online: } \\
\hline 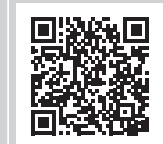 & $\begin{array}{l}\text { Scan this QR } \\
\text { code with your } \\
\text { smart phone or } \\
\text { mobile device } \\
\text { to read online. }\end{array}$ \\
\hline
\end{tabular}

Background: Despite the fact that adherence to antipsychotic medications is the cornerstone in the treatment and prevention of relapse of the disease, non-adherence is a major problem among schizophrenia patients. The purpose of this study was to assess the magnitude and factors associated with antipsychotic medication non-adherence among schizophrenia patients in Amanuel Mental Specialized Hospital.

Method: An institution-based cross-sectional study was conducted among 412 people with schizophrenia at Amanuel Mental Specialized Hospital from April to May 2014. Non-adherence was assessed using the questionnaire of Morisky medication adherence rating scale and semistructured questions for assessment of associated factors. Logistic regression analysis was used to assess predictors of non-adherence.

Results: Prevalence of non-adherence was $41.0 \%$ among schizophrenia patients. Living in rural areas (adjusted odds ratio $[\mathrm{AOR}]=2.07 ; 95 \%$ confidence interval $[\mathrm{CI}]: 1.31,3.28$ ), current substance use $(\mathrm{AOR}=1.67 ; 95 \% \mathrm{CI}: 1.09,2.56)$, long duration of treatment $(\mathrm{AOR}=2.07 ; 95 \% \mathrm{CI}$ : $1.22,3.50)$ and polypharmacy (AOR $=2.13 ; 95 \%$ CI: $1.34,3.40)$ were found to be significantly associated with non-adherence.

Conclusion: The results indicate that non-adherence to antipsychotic medication was a major problem among patients with schizophrenia. Reducing the number of antipsychotic medications and availing drugs in rural areas may decrease the level of non-adherence.

\section{Introduction}

Schizophrenia is a severe illness which affects all life aspects of the patients including work, selfcare and capacity to establish interpersonal relationships. ${ }^{1}$ It is one of the top 10 causes of longterm disability in the world, affecting about $1.0 \%$ of the population. ${ }^{2}$

Antipsychotic drugs have become the cornerstone of treatment for schizophrenia. These are effective in reducing psychotic symptoms, preventing psychotic relapses and improving psychosocial functioning. ${ }^{3}$ However, non-adherence to medication is one of the biggest problems, increasing rehospitalisation and persistent psychotic symptoms, and the most challenging aspect of treatment. ${ }^{4,5,6}$

Non-adherence can cause high rates of relapse within 5 years of recovery from the first episode. ${ }^{7}$ Thus, lack of adherence to pharmacological treatment is associated with worsening of symptoms, poor prognosis, high costs and unnecessary adjustments in the medical prescriptions. ${ }^{8}$

A report in Poland revealed that treatment adherence in the first month was very low, but application of telemedicine monitoring systems would improve the compliance in patients with the worst compliance. ${ }^{9}$ Many studies reported that the level of medication adherence for antipsychotic treatment was ranged from $20.0 \%$ to $70.0 \%{ }^{10,11,12}$

Different reports in Ethiopia have shown that non-adherence to antipsychotics medication was varied from $26.5 \%$ to $47.9 \%{ }^{13,14,15,16}$ Other qualitative studies showed that medication side effects, poverty, lack of family supports, duration of illness and stigma, substance use, alcohol consumption and smoking are some of the factors affecting the medication adherence of schizophrenia. ${ }^{17}$ Thus, non-adherence remains a challenge for patients with psychiatric disorders and their health care providers, contributing to a substantial worsening of disease, frequent relapse, increased mortality, re-hospitalisation and increased health care costs. ${ }^{18}$

The magnitude and consequences of non-adherence to antipsychotic drugs among schizophrenia patients vary from one place to another, suggesting the need of study in the local context. However, 
there is limited evidence in the study area. Therefore, this study was intended to fill the gap by assessing the magnitude and factors associated with antipsychotic medication nonadherence among people with schizophrenia at Amanuel Mental Specialized Hospital (AMSH).

\section{Methods}

\section{Study setting and design}

A cross-sectional study design was used at AMSH from April to May 2014. AMSH is one of the pioneer Ethiopian hospitals, established in 1938 by the Italians. The hospital is playing its pivotal role as a training institute for psychiatric professionals so as to expand the service throughout the country by introducing psychiatry services in the primary health care system of the country. Annually, about 51204 schizophrenia patients visited the hospital for regular follow-up services at outpatient departments, and, on average, 4267 schizophrenia patients had monthly follow-ups. All schizophrenia patients who had regular follow-up at AMSH were taken as a source population, while those schizophrenia patients who were available during data collection were considered as a study population. Schizophrenia patients aged above or equal to 18 years, who had one or more previous visits and who were on follow-up during the study period at outpatient departments of AMSH were recruited for the study. However, patients with serious medical or neurological illnesses, who had no insight and who were unable to communicate were excluded from the study.

\section{Sample size determination and procedure}

A single population proportion formula $\left\{\left[Z^{2 *} p^{*}(1-p)\right] / d 2\right\}$ with an assumption of $95.0 \%$ confidence level, $5 \%$ margin of error and $50 \%$ proportion of schizophrenia patients with non-adherence to their medication( $p$ ) and 10\% non-response rate was used to determine the final sample size of 423 .

The total number of schizophrenia patients who visited the hospital over the previous 6 months was taken from records and the average number of patients per month was calculated and found to be 4267 . Therefore, systematic random sampling technique was used to include every 10th $(4267 / 423=10)$ schizophrenia patient available at the clinic during the data collection period.

\section{Data collection method and instrument}

Data were collected using a semi-structured and pretested questionnaire by face-to-face interview technique. Chart review was used to collect the type and number of antipsychotic drugs and duration of medication. Two trained psychiatry nurses working in the mood disorder department of the hospital collected the data for a period of approximately 1 month. The questionnaire included socio-demographic data, Morisky medication adherence rating scale (MMARS)8 items and semi-structured questions for assessment of associated factors. MMARS- 8 is extensively used to measure non-adherence in Ethiopia. ${ }^{19,20,21}$ The cut-off point of 3 and above was used to define non-adherence in this study. The questionnaire was translated into Amharic and back to English by language experts and a psychiatrist for checking its consistency.

\section{Data quality assurance and analysis}

Data were entered to Epi Info version 3.5 after checking for completeness and then exported to SPSS version 20 for further analysis. Descriptive statistics analysis was performed for variables and the results were presented using tables, percentage, mean and standard deviation. Bivariate logistic regression was first conducted to identify potential confounding factors and variables with a $p<0.2$ were entered to multivariable logistic regression models using backward selection method to identify factors associated with nonadherence. An adjusted odds ratio with $95.0 \%$ confidence interval was used to interpret the strength and significance of the association.

\section{Ethical considerations}

Ethical clearance was obtained from the ethical research review committee of the University of Gondar and Amanuel Mental Specialized Hospital. Written consent was obtained from each study participant during data collection. The purpose and procedure of the study were clearly explained to all the participants. The participants were assured that their identity would remain anonymous and their responses would be kept confidential. The right was given to participants to decide whether they wish to be part of the research or not. Furthermore, they were assured that they can withdraw from the study at any time and it would not have any effect on their next follow-up treatment.

\section{Results}

\section{Socio-demographic characteristics of schizophrenia patients}

Out of the total 423 recruited patients, 412 filled in the questionnaire completely, giving a response rate of $97.4 \%$. The mean age of schizophrenia patients was 35.28 years with a standard deviation of 10.35 years. Most $(68.0 \%)$ of the respondents were living in urban areas, single (65.5\%) and orthodox religion followers (56.1\%). About half of the respondents $(47.6 \%)$ were jobless and nearly four in every five $(73.3 \%)$ were earning less than 750 Ethiopian birr / month (less than US\$33) (Table 1).

\section{Clinical and patient-related factors}

Among the study participants, about half (48.1\%) had been taking medication for fewer than 5 years. Nearly one-third $(28.2 \%)$ of the participants were on antipsychotic polypharmacy (use of two or more antipsychotic drugs at a time). On the other hand, $29.6 \%$ of the participants had history of previous psychiatric admissions and history of substance use since initiation of treatment (39.3\%) (Table 2). 
TABLE 1: Distribution of socio-demographic characteristics of schizophrenia patients attending at Amanuel Mental Specialized Hospital, Addis Ababa, Ethiopia, June $2014(n=412)$.

\begin{tabular}{|c|c|c|}
\hline Variable & Frequency & $\%$ \\
\hline \multicolumn{3}{|l|}{ Sex } \\
\hline Male & 287 & 69.7 \\
\hline Female & 125 & 30.3 \\
\hline \multicolumn{3}{|l|}{ Age } \\
\hline$\leq 25$ & 71 & 17.2 \\
\hline $26-35$ & 163 & 39.6 \\
\hline$\geq 36$ & 178 & 43.2 \\
\hline \multicolumn{3}{|l|}{ Marital status } \\
\hline Single & 270 & 65.5 \\
\hline Married & 80 & 19.4 \\
\hline Divorced & 32 & 7.8 \\
\hline Widowed & 6 & 1.5 \\
\hline \multicolumn{3}{|l|}{ Residence } \\
\hline Urban & 280 & 68.0 \\
\hline Rural & 132 & 32.0 \\
\hline \multicolumn{3}{|l|}{ Ethnicity } \\
\hline Amhara & 148 & 35.9 \\
\hline Oromo & 112 & 27.2 \\
\hline Gurage & 93 & 22.4 \\
\hline Tigre & 21 & 5.1 \\
\hline Others & 38 & 9.2 \\
\hline \multicolumn{3}{|l|}{ Educational status } \\
\hline Uneducated & 49 & 11.9 \\
\hline $1-8$ grades & 126 & 30.6 \\
\hline 9-12 grades & 157 & 38.1 \\
\hline Diploma and above & 80 & 19.4 \\
\hline \multicolumn{3}{|l|}{ Occupation } \\
\hline Employed & 68 & 16.5 \\
\hline Private business & 70 & 17.0 \\
\hline Daily labourer & 37 & 9.0 \\
\hline Jobless & 196 & 47.6 \\
\hline Student & 20 & 4.9 \\
\hline Housewife & 21 & 5.1 \\
\hline \multicolumn{3}{|c|}{ Monthly income (Ethiopian birr) } \\
\hline$<750$ birr & 302 & 73.3 \\
\hline 750 birr-1199 birr & 47 & 11.4 \\
\hline$\geq 1200$ birr & 63 & 15.3 \\
\hline
\end{tabular}

\section{Substances use among schizophrenia patients}

Compared to alcohol use, current use of khat chewing and smoking cigarettes simultaneously were found to be high among non-adherent schizophrenia patients (Figure 1). Khat (chat) is one of the most common forms of drug use and abuse in many East African nations, especially in Ethiopia, involving chewing parts of the fresh green leaves. Chewing khat has stimulant and euphoric effects and is believed to have a relaxing effect, to increase concentration and is used to waste time.

\section{Factors associated with antipsychotic non-adherence}

Prevalence of non-adherence was found to be $41.0 \%$ among schizophrenia patients in this study. Bivariate logistic regression analysis was performed to find the relationship of socio-demographic, patient and treatment-related variables with non-adherence of antipsychotics. The result of bivariate analysis revealed that place of residence,
TABLE 2: Distribution of clinical and patient-related factors among schizophrenia patients at Amanuel Mental Specialized Hospital, Addis Ababa, Ethiopia, June $2014(n=412)$

\begin{tabular}{|c|c|c|c|}
\hline Variable & & Frequency & $\%$ \\
\hline \multirow[t]{2}{*}{ Duration of illness } & $<3$ years & 78 & 18.9 \\
\hline & $\geq 3$ years & 334 & 81.1 \\
\hline Antipsychotic & yes & 116 & 28.2 \\
\hline polytherapy & No & 296 & 71.8 \\
\hline \multirow[t]{3}{*}{ Duration of treatment } & $<2$ years & 111 & 26.9 \\
\hline & 2-5 year & 87 & 21.1 \\
\hline & $>5$ years & 214 & 51.9 \\
\hline \multirow[t]{5}{*}{ Type of antipsychotics } & FGA & 250 & 60.7 \\
\hline & SGA & 46 & 11.2 \\
\hline & $\mathrm{FGA}+\mathrm{FGA}$ & 96 & 23.3 \\
\hline & $\mathrm{FGA}+\mathrm{SGA}$ & 19 & 4.6 \\
\hline & $\mathrm{FGA}+\mathrm{FGA}+\mathrm{SGA}$ & 1 & 0.2 \\
\hline \multirow[t]{2}{*}{ Route of antipsychotics } & Oral & 368 & 89.3 \\
\hline & Injectable $\dagger$ & 44 & 10.7 \\
\hline \multirow[t]{3}{*}{ Number of admissions } & None & 290 & 70.4 \\
\hline & One & 66 & 16.0 \\
\hline & $\geq$ two & 56 & 13.6 \\
\hline \multirow[t]{2}{*}{ EPS } & Yes & 43 & 10.4 \\
\hline & No & 369 & 89.6 \\
\hline \multirow[t]{2}{*}{ Drug adherence } & Yes & 243 & 59.0 \\
\hline & No & 169 & 41.0 \\
\hline \multirow[t]{2}{*}{ Substance use } & No & 250 & 60.7 \\
\hline & Yes & 162 & 39.3 \\
\hline
\end{tabular}

EPS, Extrapyramidal side effects; FGA, first generation antipsychotics; SGA, second generation antipsychotics.

$\dagger$, fluphenazine decanoate.

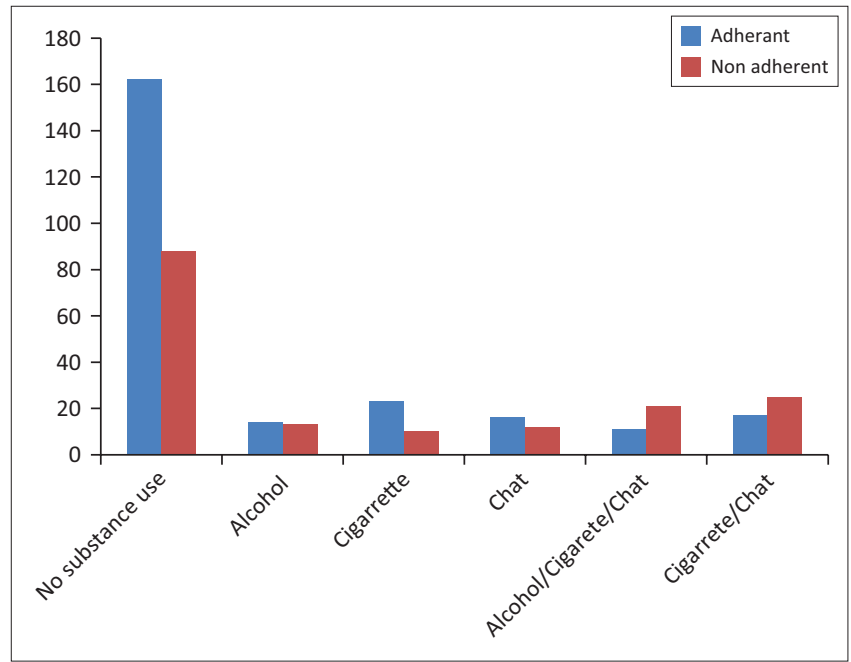

FIGURE 1: Bar chart showing the distribution of substance use among schizophrenia patients at Amanuel Mental Specialized Hospital, Addis Ababa, Ethiopia, June 2014 ( $n=412$ ).

duration of illness, duration of treatment, number of psychiatric hospitalisation days, history of active substance use, only injectable antipsychotic use (fluphenazine decanoate) and antipsychotic polypharmacy were factors significantly associated with non-adherence. However, in multivariate logistic regression, place of residence, history of active substance use, duration of treatment and antipsychotic polypharmacy were found to be statistically significant.

Accordingly, patients who were living in rural areas were about twice as likely to be non-adherent to antipsychotic 
TABLE 3: Factors associated with antipsychotic polypharmacy among schizophrenia outpatients under follow-up at Amanuel Mental Specialized Hospital, Addis Ababa, Ethiopia, June $2014(n=412)$

\begin{tabular}{|c|c|c|c|c|c|}
\hline \multirow[t]{2}{*}{ Variable } & & \multicolumn{2}{|c|}{ Adherence } & \multicolumn{2}{|c|}{ Odd ratio at $95 \% \mathrm{Cl}$} \\
\hline & & Yes & No & Crude & Adjusted \\
\hline \multirow[t]{2}{*}{ Residence } & Urban & 178 & 102 & 1 & 1 \\
\hline & Rural & 65 & 67 & $1.79(1.18,2.73)$ & $2.07(1.31,3.28)^{*}$ \\
\hline Substance use (khat & No & 162 & 88 & 1 & 1 \\
\hline Alcohol and tobacco) & Yes & 81 & 81 & $1.84(1.23,2.75)$ & $1.67(1.09,2.56)^{*}$ \\
\hline \multirow[t]{3}{*}{ Duration of illness } & $<5$ years & 95 & 48 & 1 & 1 \\
\hline & $5-10$ years & 53 & 57 & $2.12(1.27,3.54)$ & $1.75(0.89,3.47)$ \\
\hline & $>10$ years & 95 & 64 & $1.33(0.83,2.13)$ & $1.64(0.66,4.06)$ \\
\hline \multirow[t]{3}{*}{ Number of admissions } & None & 176 & 114 & 1 & 1 \\
\hline & One & 40 & 26 & $1.00(0.58,1.73)$ & $0.83(0.46,1.49)$ \\
\hline & $\geq$ Two & 27 & 29 & $1.65(0.93,2.94)$ & $1.24(0.66,2.35)$ \\
\hline \multirow[t]{3}{*}{ Duration of treatment } & $<5$ years & 126 & 72 & 1 & 1 \\
\hline & $5-10$ years & 42 & 53 & $2.20(1.34,3.63)$ & $2.07(1.22,3.50)^{*}$ \\
\hline & $>10$ years & 75 & 44 & $1.02(0.64,1.64)$ & $1.04(0.62,1.74)$ \\
\hline Route of antipsychotics & Injectable & 31 & 13 & 1 & 1 \\
\hline Antipsychotics & No & 191 & 105 & 1 & 1 \\
\hline polypharmacy & Yes & 52 & 64 & $2.23(1.44,3.46)$ & $2.13(1.34,3.40) *$ \\
\hline
\end{tabular}

1 , Reference; $\mathrm{Cl}$, confidence interval.

$* p<0.05$

medication as compared to those living in urban areas $(\mathrm{AOR}=2.07 ; 95 \% \mathrm{CI}: 1.31,3.28)$.

Regarding substance use, patients who were using psychoactive substances after initiation of treatment were nearly twice as likely to be non-adherent to antipsychotic medication compared to those who had no history of substance use $(\mathrm{AOR}=1.67,95 \% \mathrm{CI}: 1.09,2.56)$.

Moreover, participants who took medication for more than 5 years were twice as likely to be non-adherent to antipsychotic medication as compared to those who took for less than 5 years $(\mathrm{AOR}=2.07,95 \% \mathrm{CI}: 1.22,3.50)$.

Patients who were on antipsychotic polypharmacy were two times more likely to be non-adherent to their medication as compared to those who were on a single drug $(\mathrm{AOR}=2.13$, 95\% CI: 1.34, 3.40) (Table 3).

\section{Discussion}

Antipsychotic medication is the mainstay in the treatment of schizophrenia, and adherence to medication plays a pivotal role in controlling symptoms and preventing frequent relapses. From the finding of the present study, the magnitude of non-adherence among schizophrenia patients was found to be $41.0 \%$ (95\% CI: $36.2 \%, 45.6 \%)$. Although it is clear that more than one factor is responsible for non-adherence among schizophrenia patients, place of residence, active substance use, duration of treatment and antipsychotic polypharmacy were the main factors identified in the current study.

This finding of this study was in line with the study conducted in Switzerland (44.8\%). ${ }^{22}$ However, it is by far lower than the studies conducted in Egypt (74.0\%), Jordan (64.2\%), ${ }^{13}$ Nigeria $(51.7 \%-62.5 \%)^{12,24}$ and Bulgaria $\left.(55.8 \%)\right)^{25}$ The possible explanation behind this might be theinclusion criteria.
In Nigeria, comorbid psychoactive substance use and patients who had been on medication for less than 1-year were included, whereas schizophrenia patients who had more than one visit were included in our study. Furthermore, comorbid psychoactive substance use was investigated as an influencing factor for adherence in this study. The study conducted in Egypt also used a convenience sampling technique, suggesting the possible reason for the observed difference. In Bulgaria, 226 schizophrenia patients on longterm antipsychotic treatment were included, while the exclusion criteria were first episode of psychosis, substance dependence, date of the last hospitalisation less than 2 months prior to the study and change in type or dose of antipsychotic medication within the previous month. Furthermore, these discrepancies might be because of the difference in study participants, culture, time variation and settings.

The current estimate is larger than the result from studies conducted in France $(30.0 \%),{ }^{26}$ Jimma, Southwest Ethiopia $(36.0 \%)^{15}$ and Mekelle, Northern Ethiopia (26.5\%). ${ }^{13}$ This might be because of the difference in study design, study setting, study year, socio-demographic data and type of screening tool used. The study performed in Mekelle had quite low rates of non-adherence that could be explained by differences in measuring medication adherence methods and sample size. The major difficulty in categorising the magnitude of non-adherence in schizophrenia patients is the lack of consistent and agreed criteria. For instance, the 10-item modified version of the Morisky Medication Adherence Scale (MMAS) was used in Mekelle, which was answered using 'yes/no' responses. A MMAS score equal to 3 or above indicated adherence, while less than or equal to 2 indicated non-adherence. However, in the current study, an 8-item MMAS with seven 'yes/no' questions and one question answered on a five-point Likert scale was used. In addition, the sample size variation and inclusion criteria might account for this difference. 
A number of factors were significantly associated with nonadherence to antipsychotic medication. In this study, schizophrenia patients living in rural areas were found to be non-adherent compared to urban residents, which is supported by another study. ${ }^{27}$ The possible explanation might be related to long distance to health facilities, financial constraints to purchase medication, lack of services for mental health care and low community awareness regarding treatment of mental illness, which are more common in rural areas.

In addition, schizophrenia patients chewing chat, drinking alcohol and smoking cigarettes were non-adherent to their medications, which is in line with different studies. ${ }^{4,17}$ There was a significant negative relationship between substance abuse and non-adherence. ${ }^{28}$ Patients non-adherent to their medications were found to have higher percentage of present or past substance abuse. ${ }^{29}$

Furthermore, long duration of treatment and use of two or more antipsychotic drugs at a time were related to nonadherence, which was supported by a study conducted in Nigeria. ${ }^{12}$

The present study has some limitations. It was crosssectional; therefore, temporal relationship between risk factors and non-adherence cannot be determined. Although we used psychiatry nurses working in the mood disorder department for data collection within the same hospital, it might have some information and recall biases. The patients' report method used to measure treatment non-adherence might underestimate its magnitude compared to plasma concentrations.

\section{Conclusion}

The aim of this study was to assess the prevalence and main factors associated with non-adherence. Thus, adherence to antipsychotics medication among patients with schizophrenia was a major problem in this study. Living in rural areas, substance use, long duration of treatment and taking more than one antipsychotic medication were the most important factors for increased non-adherence. Reducing the number of antipsychotic medications and availing drugs in rural areas may decrease the level of non-adherence. Furthermore, clinicians should emphasise the importance of screening of patients for substance abuse and offer brief motivational interventions for those in need of addiction rehabilitation services, which might lead to better adherence to their medications.

\section{Acknowledgements}

The authors would like to thank Bahir Dar University for providing facilities. They also thank the participants and data collectors for their time and participation in the study.

\section{Competing interests}

The authors declare that they have no financial or personal relationships which may have inappropriately influenced them in writing this article.

\section{Authors' contributions}

All authors contributed towards data analysis, drafting and critically revising the article and agreed to be accountable for all aspects of the work.

\section{References}

1. Catts S, Weickert CS. Schizophrenia and related psychotic disorders. Oxford University Press, 2017; p. 113-130.

2. Nicolino PS, Vedana KGG, Miasso Al, Cardoso L, Galera SAF. Schizophrenia: Adherence to treatment and beliefs about the disorder and the drug treatment. Rev Esc Enferm USP. 2011;45(3):708-715. https://doi.org/10.1590/s008062342011000300023

3. Gilbert PL, Harris MJ, McAdams LA, Jeste DV. Neuroleptic withdrawal in schizophrenic patients: A review of the literature. Arch Gen Psychiatry. 1995;52(3):173-188. https://doi.org/10.1001/archpsyc.1995.03950150005001

4. Higashi K, Medic G, Littlewood KJ, Diez T, Granström O, De Hert M. Medication adherence in schizophrenia: Factors influencing adherence and consequences of nonadherence, a systematic literature review. Ther Adv Psychopharmacol. 2013;3(4):200-218. https://doi.org/10.1177/2045125312474019

5. Morken G, Widen JH, Grawe RW. Non-adherence to antipsychotic medication, relapse and rehospitalisation in recent-onset schizophrenia. BMC Psychiatry. 2008;8(1):32. https://doi.org/10.1186/1471-244X-8-32

6. Thornicroft $G$, Tansella M, Becker T, et al. The personal impact of schizophrenia in Europe. Schizophr Res. 2004;69(2):125-132. https://doi.org/10.1016/S09209964(03)00191-9

7. Srinivasan TN, Thara R. At issue: Management of medication noncompliance in schizophrenia by families in India. Schizophr Bull. 2002;28(3):531. https://doi. org/10.1093/oxfordjournals.schbul.a006960

8. Silva TFCD, Lovisi GM, Verdolin LD, Cavalcanti MT. Adherence to drug treatment among schizophrenic spectrum patients: A systematic review of the literature. J Bras Psiquiatr. 2012;61(4):242-251. https://doi.org/10.1590/S0047-208520 12000400008

9. Krzystanek M, Krzeszowski D, Jagoda K, Krysta K. Long term telemedicine study of compliance in paranoid schizophrenia. Psychiatr Danub. 2015;27:266-268.

10. Kemmler G, Hummer M, Widschwendter C, Fleischhacker WW. Dropout rates in placebo-controlled and active-control clinical trials of antipsychotic drugs: A meta-analysis. Arch Gen Psychiatry. 2005;62(12):1305-1312. https://doi.org/ 10.1001/archpsyc.62.12.1305

11. Amr M, El-Mogy A, El-Masry R. Adherence in Egyptian patients with schizophrenia: The role of insight, Medication beliefs and spirituality. Arab J Psychiatr. 2013;24:60-68. https://doi.org/10.12816/0000100

12. Ibrahim A, Pindar S, Yerima M, et al. Medication-related factors of non adherence among patients with schizophrenia and bipolar disorder: Outcome of a crosssectional survey in Maiduguri, North-eastern Nigeria. J Neurosci Behav Health. 2015;7(5):31-39. https://doi.org/10.5897/JNBH2015.0128

13. Eticha T, Teklu A, Ali D, Solomon G, Alemayehu A. Factors associated with medication adherence among patients with schizophrenia in Mekelle, Northern Ethiopia. PLoS One. 2015;10(3):e0120560. https://doi.org/10.1371/journal.pone. 0120560

14. Demoz Z, Legesse B, Teklay G, et al. Medication adherence and its determinants among psychiatric patients in an Ethiopian referral hospital. Patient Prefer Adherence. 2014;8:1329-1335.

15. Tesfay K, Girma E, Negash A, Tesfaye M, Dehning S. Medication non-adherence among adult psychiatric out-patients in Jimma University specialized hospital, Southwest Ethiopia. Ethiopian J Health Sci. 2013;23(3):227-236. https://doi.org/ Southwest Ethiopia.
$10.4314 /$ ejhs.v23i3.5

16. Alene M, Wiese MD, Angamo MT, Bajorek BV, Yesuf EA, Wabe NT. Adherence to medication for the treatment of psychosis: Rates and risk factors in an Ethiopian population. BMC Pharmacol Toxicol. 2012;12(1):10. https://doi.org/10.1186/1472population.

17. Teferra S, Hanlon C, Beyero T, Jacobsson L, Shibre T. Perspectives on reasons for non-adherence to medication in persons with schizophrenia in Ethiopia: A qualitative study of patients, caregivers and health workers. BMC Psychiatry. A qualitative study of patients, caregivers and health worke
2013;13(1):1. https://doi.org/10.1186/1471-244X-13-168

18. Chapman SC, Horne R. Medication nonadherence and psychiatry. Curr Opinion in Psychiatry. 2013;26(5):446-452. https://doi.org/10.1097/YCO.0b013e3283642da4

19. Kebede MA, Haidar J. Factors influencing adherence to the food by prescription program among adult HIV positive patients in Addis Ababa, Ethiopia: A facilitybased, cross-sectional study. Infect Dis Poverty. 2014;3(1):20. https://doi.org/ 10.1186/2049-9957-3-20

20. Hasiso TY, Desse TA. Adherence to treatment and factors affecting adherence of Epileptic patients at Yirgalem General Hospital, Southern Ethiopia: A prospective cross-sectional study. PLoS One. 2016;11(9):e0163040. https://doi.org/10.1371/ journal.pone. 0163040

21. Getnet A, Meseret S, Bekana L, et al. Antiepileptic drug nonadherence and its predictors among people with epilepsy. Behav Neurol. 2016;2016:1-6. https:// doi.org/10.1155/2016/3189108

22. Simona $A E$, Peterb $M$, Hessb $L$, Valterioc $C$. Antipsychotic use in patients with schizophrenia treated in private psychiatry. Swiss Med Wkly. 2005;135: 109-115 
23. Mukattash TL, Alzoubi KH, Abu El-Rub E, et al. Prevalence of non-adherence among psychiatric patients in Jordan, a cross sectional study. Int J Pharm Pract. 2016;24(3):217-221. https://doi.org/10.1111/ijpp.12239

24. Effiong JH, Umoh KA. Medication non adherence in schizophrenia: Prevalence and correlates among outpatients in a tertiary healthcare facility in Uyo, South-South Nigeria. Clin Med Diagn. 2015;5(6):107-113.

25. Vassileva I, Milanova V, Asan T. Predictors of medication non-adherence in bulgarian outpatients with schizophrenia. Community Mental Health J. 2014;50(7):854-861. https://doi.org/10.1007/s10597-014-9697-8

26. Dassa D, Boyer L, Benoit $M$, Bourcet $S$, Raymondet $P$, Bottai T. Factor associated with medication non-adherence in patients suffering from schizophrenia: A cross-sectional study in a universal coverage health-care system. Aust N Zeal J Psychiatry. 2010;44(10):921-928. https://doi.org/10.310 9/00048674.2010.493503

27. Wang $\mathrm{X}$, Zhang $\mathrm{W}, \mathrm{Ma} \mathrm{N}$, et al. Adherence to antipsychotic medication by community-based patients with schizophrenia in China: A cross-sectional study. Psychiatr Serv. 2016;67(4):431-437. https://doi.org/10.1176/appi.ps.201500056

28. Janssen B, Gaebel W, Haerter M, Komaharadi F, Lindel B, Weinmann S. Evaluation of factors influencing medication compliance in inpatient treatment of psychotic disorders. Psychopharmacology. 2006;187:229-236. https://doi.org/10.1007/ s00213-006-0413-4

29. Ascher-Svanum H. A prospective study of risk factors for nonadherence with antipsychotic medication in the treatment of schizophrenia. J Clin Psychiatry 2006;67:1114-1123. https://doi.org/10.4088/JCP.v67n0715 